\title{
Mental health service discrimination against older people
}

\author{
David Anderson, ${ }^{1}$ Peter Connelly, ${ }^{2}$ Richard Meier, ${ }^{3}$ Cherie McCracken ${ }^{4}$
}

The Psychiatrist (2013), 37, 98-103, doi: 10.1192/pb.bp.112.040097

${ }^{1}$ Mersey Care NHS Trust, Liverpool; ${ }^{2}$ Murray Royal Hospital, Perth; ${ }^{3}$ Royal College of Psychiatrists, London; ${ }^{4}$ Institute of Psychology, Health and Society, University of Liverpool

Correspondence to David Anderson (david.anderson@merseycare.nhs.uk)

First received 14 May 2012, accepted 10 Aug 2012

\begin{abstract}
Aims and method To provide a picture of availability and equality of access to mental health services for older people prior to the Equality Act. In 2010, a questionnaire was sent to health commissioners in England, Scotland and Wales under a Freedom of Information request.
\end{abstract}

Results Overall, $132(76 \%)$ replied. Of 11 services, 7 were either unavailable or did not provide equality of access to older people in more than a third of commissioning areas. When provided by specialist older people's mental health, services were more often considered to ensure equality.

Clinical implications Increasing need resulting from an ageing population is unlikely to be met in the face of current inequality. Inequality on the basis of age is the result of government policy and not the existence of specialist services for older people. Single age-inclusive services may create indirect age discrimination. Availability alone is insufficient to demonstrate equality of access. Monitoring the effects of legislation must take this into account.

Declaration of interest The survey was conducted by the Policy Unit of the Royal College of Psychiatrists on behalf of the Faculty of the Psychiatry of Old Age, Royal College of Psychiatrists. All authors were involved with developing the questionnaire and preparation of the paper. D.A. and P.C. were elected members serving on the Executive Committee of the Faculty at the time the study was conducted. R.M. was Policy Analyst with the Royal College of Psychiatrists at the time of the study.
Mental health services in the UK have developed into specialist services for older people, usually defined as those over the age of 64 years, and separate specialist services for adults aged 18-64 years. There is unequivocal evidence of discrimination against older people in mental health services in the UK fuelled by the approach to national policy implementation, which has promoted the needs of working-age adults and excluded older people. ${ }^{1}$ Independent reports demonstrate that when older and younger adults in England with equivalent need are compared, then older people have less access to mental health and social care services, and to redress that inequality would cost $£ 2-4$ billion of public money per year. ${ }^{2,3}$

Yet the ageing population presents the major challenge to health and social care services now and for decades to come. By 2026, the only increase predicted in the number of people with any form of mental disorder will occur by virtue of the rising number of older people. ${ }^{4}$ The need for more specialists in old age psychiatry is recognised in advice to the UK government, recommending that the greatest increase in the number of psychiatry training posts and consultant psychiatrists to 2018 is in the specialty of old age psychiatry. ${ }^{5}$ This shortage of specialists trained in this area is internationally widespread. ${ }^{6}$
In 2001, the National Service Framework (NSF) for Older People ${ }^{7}$ was published, with a 10-year lifespan, as the national health strategy for England and Wales and included one section (Standard 7) on mental health, specifically dementia and depression. Three years later a national survey of old age psychiatrists in England found that little had changed ${ }^{8}$ and this strategy has never been delivered. ${ }^{9}$ This contrasts with the substantial increase in investment, clinical staff, new services and better clinical outcomes reported after implementation of the NSF for Mental Health, the equivalent mental health strategy for adults under the age of 65 , published 2 years earlier. ${ }^{10,11}$

Although only 2 years apart, the government approach to implementation of the two strategies was quite different. ${ }^{1}$ Driven by the NSF for Mental Health, substantial investment in mental health services for adults of working age that explicitly excluded older people expanded. Between 2002 and 2010 , this investment in people aged 18-64 amounts to a real term increase of $£ 2.315$ billion ( $58 \%$ increase), with a focus on three priority areas of crisis resolution home treatment (CRHT) (592\% increase), assertive outreach (89\% increase) and early intervention in psychosis ( $1274 \%$ increase), with $162 \%$ increase in access and crisis and $141 \%$ increase in secure and high-dependency services. ${ }^{12}$ 
By contrast, there has been a combined primary care trust and local authority real-term investment in older people's mental health services in England of $28 \%$ between 2006 (when separate financial mapping of these services began) and 2010, with evident inequality by region. ${ }^{13}$

The NSF for Mental Health is considered a success and brought substantial investment, whereas the NSF for Older People has never been delivered and stimulated little development of mental health services. Consequently, older people's services have fallen behind despite serving the population where numbers and need have increased. This was acknowledged by national clinical directors, ${ }^{14,15}$ although never addressed. The NSFs have been replaced by a mental health strategy that takes a lifespan approach, while emphasising that services must remain age and developmentally appropriate and not be based on an assumption that 'one size fits all'. ${ }^{16}$

UK equality legislation makes unjustified discrimination on the basis of age unlawful and mental health services will need to review the way they operate. Making judgements solely on the basis of age is likely to be unjustified direct age discrimination. However, a failure to recognise the relevance of age as a personal characteristic and deliver exactly the same service to all adults regardless of age, might amount to unjustified indirect age discrimination, often referred to as 'the chilling effect' or age-blind approach.,17 To avoid both direct and indirect forms of discrimination, services will need to be age appropriate avoiding the 'one size fits all' approach and, at the same time, not exclude people on the basis of their age alone. ${ }^{1,9,16-22}$

In anticipation of new legislation in the UK, it is important to have a picture of the extent of discrimination at the level of service delivery at this point in time to provide a comparator against which the effect of legislation may be measured. The reported survey provides a servicelevel picture of the availability and equality of access to services for older people.

\section{Method}

In 2010, a Freedom of Information request was sent to all primary care trusts, health boards and National Health Service (NHS) boards (commissioners) in England ( $n=143$ ), Wales $(n=9)$ and Scotland $(n=21)$ respectively, requesting information on the availability of a range of mental health services. They were then asked for their opinion on whether people aged 65 and over had equality of access to these services compared with adults under age 65 years and whether these services were provided by a specialist older people's mental health service or a single age-inclusive service. This information was requested for 11 services: in-patient, out-patient, community mental health team (CMHT), CRHT (24 hours and office hours), assertive outreach, intermediate care, dedicated general hospital liaison, rehabilitation, low secure, and specialist psychotherapy. Two of the three new services introduced by the NSF for Mental Health (assertive outreach and CRHT) are included but not early intervention in psychosis as this is typically targeted at people aged under 35 .
The definition of discrimination given in the questionnaire was taken from the Royal College of Psychiatrists' position statement on age discrimination: ${ }^{19}$

'Discrimination will also exist when inequitable distribution of resources prevents services meeting needs, when older people are required to attend services not designed to meet their needs, or when older people are denied access to services available to younger people that could meet their needs.'

This was used to inform the response on whether equality of access exists for an available service.

\section{Results}

Data were returned by $132(76 \%)$ commissioners: $86 \%$ of boards in Scotland, 89\% in Wales and 74\% in England. There was at least one response from all English (strategic health authority area) regions (range 6-21).

Table 1 shows the level of availability for each service for older people and whether they are provided by older people's mental health services or single age-inclusive services. The number of services available to older people ranged from 3 to 11 (median $=7)$. All 11 services were provided by 8 commissioners (6\%), with no predominance of either older people's mental health services or single age-inclusive services, and all were in England. In-patient, out-patient and care from CMHTs were the most widely available (in $99 \%$ of areas) and most were provided by older people's mental health services. The least available service was assertive outreach and this was provided mainly by single age-inclusive services. Single age-inclusive services predominantly provided assertive outreach, 24-hour and office-hour CRHT and low secure care. The remainder of the services were predominantly provided by specialist older people's mental health services, with the exception of psychotherapy which is equally provided by both types of service. Six commissioning areas had no services declared as provided by older people's mental health services (three in England, two in Wales and one in Scotland). Similarly, 23 commissioners had no services provided by single ageinclusive services (15 in England, 5 in Wales and 3 in Scotland). In total, 1016 services were provided: 650 (64\%) by older people's mental health services, 319 (31\%) by single age-inclusive services and $47(5 \%)$ were not attributed to either service.

Of the 1016 services provided, $846(83 \%)$ were declared equitable, 74 (7\%) inequitable and for 96 (10\%) there was no declaration. Whether the total service provision for each area was considered equitable was examined by subtracting the number equitable from the number available for each commissioner. In the case of $86(65 \%)$ commissioners, the number of services available and the number equitable were the same. For the remaining 46: 29 (22\%) commissioners had 1 or 2 services that they considered were not equitable; $14(10 \%)$ had 3 or 4 services that they considered were not equitable; and of the remainder, 2 commissioners had 5 services and 1 commissioner had 9 services that were held by them to be inequitable. Only three commissioners did not declare any service to be equitable (one each in England, Wales and Scotland).

Table 2 shows whether service provision was considered to be inequitable according to the type of service 
Table 1 Availability of mental health services to older people and the percentage of available services provided by OPMHS or SAIS

\begin{tabular}{|c|c|c|c|c|c|}
\hline \multirow[t]{2}{*}{ Service } & \multicolumn{2}{|c|}{ Available } & \multicolumn{3}{|c|}{ Provided by } \\
\hline & $n$ & $\%$ & OPMHS, \% & SAIS, $\%$ & $N K, \%$ \\
\hline In-patient & 130 & 99 & 92 & 1 & 6 \\
\hline Out-patient & 131 & 99 & 92 & 2 & 5 \\
\hline CMHT & 130 & 99 & 92 & 2 & 5 \\
\hline Liaison $^{a}$ & 111 & 84 & 67 & 13 & 4 \\
\hline Psychotherapy & 90 & 68 & 33 & 30 & 5 \\
\hline CRHT office hours & 85 & 64 & 24 & 36 & 4 \\
\hline Intermediate care & 83 & 63 & 39 & 20 & 4 \\
\hline Rehabilitation & 74 & 56 & 33 & 22 & 1 \\
\hline Low secure & 70 & 53 & 7 & 42 & 4 \\
\hline CRHT 24 hours & 67 & 51 & 5 & 46 & - \\
\hline Assertive outreach & 45 & 34 & 7 & 28 & - \\
\hline Total & 1016 & & 64 & 31 & 5 \\
\hline
\end{tabular}

$\mathrm{CMHT}$, community mental health team; CRHT, crisis resolution home treatment; NK, not known; OPMHS, older people's mental health services; SAIS, single age inclusive service.

a. Dedicated general hospital liaison psychiatry service.

provided. In-patient, out-patient and care from CMHTs were considered to provide equality of access in $98-100 \%$ of cases. The highest levels of inequity are seen in assertive outreach, CRHT 24 hours and CRHT office hours $(29 \%, 27 \%$ and $20 \%$ respectively) where provision was by single ageinclusive services. When considered whether the same service is inequitable when delivered by older people's mental health services, the values were $0 \%, 14 \%$ and $10 \%$ respectively, and when tested using 95\% confidence intervals the only significant difference in level of inequity by type of provision was for assertive outreach. Overall, $16 \%$ of services provided by single age-inclusive services were considered to be inequitable $v .4 \%$ of services provided by older people's mental health services, a difference of $12 \%$.
When tested using a 95\% confidence interval, these services are likely to be considered between $7 \%$ and $16 \%$ more inequitable if delivered by single age-inclusive services.

Regression modelling was used in an attempt to explain levels of inequity as a function of both availability and type of service provision: first, with the number of inequitable services used as the dependent variable; and second, with the number of equitable services. The number of services provided by older people's mental health services, by single age-inclusive services, the number of services available and commissioning area were used as explanatory variables. The model for inequity explained little of the variability, with none of the explanatory variables significantly contributing to an explanation, possibly because there was little data. The

\begin{tabular}{|c|c|c|c|c|c|c|}
\hline Service & $\begin{array}{l}\text { Provided by } \\
\text { OPMHS, } n\end{array}$ & $\begin{array}{l}\text { Do not provide } \\
\text { equality }(A), \%\end{array}$ & $\begin{array}{l}\text { Provided by } \\
\text { SAIS, } n\end{array}$ & $\begin{array}{l}\text { Do not provide } \\
\text { equality (B), \% }\end{array}$ & $\begin{array}{c}\text { Difference in equality } \\
\text { between providers B } \\
\text { and } \mathrm{A}, \%(95 \% \mathrm{Cl})\end{array}$ & $\begin{array}{c}\text { Do not provide } \\
\text { equality (all providers } \\
\text { totalled), } \%\end{array}$ \\
\hline In-patient & 122 & 0 & 1 & 0 & 0 & 0 \\
\hline Out-patient & 122 & 0 & 3 & 0 & 0 & 0 \\
\hline CMHT & 121 & 2 & 3 & 0 & -2 & 2 \\
\hline Liaison $^{\mathrm{a}}$ & 89 & 7 & 17 & 6 & -1 & 7 \\
\hline Psychotherapy & 43 & 7 & 39 & 5 & -2 & 6 \\
\hline CRHT office hours & 32 & 10 & 47 & 20 & $10(-6$ to 27$)$ & 15 \\
\hline Intermediate care & 51 & 13 & 26 & 13 & 0 & 12 \\
\hline Rehabilitation & 44 & 10 & 29 & 11 & 1 & 10 \\
\hline Low secure & 9 & 13 & 56 & 9 & -4 & 9 \\
\hline CRHT 24 hours & 7 & 14 & 60 & 27 & $13(-16$ to 41$)$ & 24 \\
\hline Assertive outreach & 10 & 0 & 38 & 29 & 29 (14 to 44$)$ & 21 \\
\hline Total & 650 & 4 & 319 & 16 & 12 (7 to 16$)$ & 8 \\
\hline
\end{tabular}

CMHT, community mental health team; CRHT, crisis resolution home treatment; OPMHS, older people's mental health services; SAIS, single-age inclusive service. a. Dedicated general hospital liaison psychiatry service. 
model for equity, viable only because of missing data (i.e. equity is not the reverse of inequity in this situation), was a better model in that more of the variability was explained. The only important variable in the explanation of equity was availability $(B=0.8,95 \%$ CI $0.6-1.0)$, reflecting the significant linear correlation between the two variables of $r=0.71(P<0.01)$ explaining $50 \%$ of the variance between equity and availability.

The data show there is wide variation in availability and equality of access between commissioning areas. Additional data available from the author and not given here show that there is also wide variation in availability and equality of access within commissioning areas, confirming that the postcode lottery remains prevalent.

\section{Discussion}

The main determinant of perceived equality of access is availability. Cleary, if a service is not available to one group, there cannot be equality of access. However, as availability only explains $50 \%$ of the variance, it is not a sufficient measure of equality. In-patient, out-patient and CMHT services were almost universally available, with the highest ratings for equality and almost always provided by older people's mental health services. With the exception of four (in-patient, out-patient, CMHT, hospital liaison), more than a third reported that the other services were either unavailable or had inequality of access for older people, and for five services (office and 24-hour CRHT, rehabilitation, low secure, assertive outreach) $50 \%$ or less confirmed availability and equality of access (Tables 1 and 2). That these data show that even available services are considered inequitable indicates that monitoring the effects of equality legislation will need to take account of more than just availability.

The greatest inequality is for CRHT and assertive outreach services preferentially developed to serve the needs of younger adults, supporting the notion that discrimination has been created by previous governments' policy approach. When these services are available when provided by older people's mental health services, not single age-inclusive services, then inequality is less, although only significant for assertive outreach. That this difference is not statistically significant is a function of small numbers and thus low power (approximately 15\% when testing CRHT office hours and 17\% when testing CRHT 24 hours) and not necessarily indicative of no difference.

Where CRHT services are provided by older people's mental health services they are more likely than single ageinclusive services to attend to the needs of older people, at least in terms of the number of people served. In 2006, ${ }^{23}$ $31.6 \%$ (25 services) of mental health trusts in England provided some form of CRHT access for older people, although half of these saw less than one older person per week. Overall, $21.5 \%$ (17 services) had a policy to provide younger and older people with the same service, although only 5 were actually seeing an older person at the time of evaluation, none were seeing people with dementia and all but 2 specifically excluded people with dementia. Conversely, $8.8 \%$ (7 services) with a specialist older people's CRHT had a median case-load of 16 , although only 1 was available
24 hours. These differences would suggest older people have a need for these services which is not met by a single age-inclusive service.

In the present survey, $51 \%$ of commissioners reported 24-hour access for older people (67 services) but only 7 were provided by older people's mental health services, the same as the number in England in 2006. Crisis resolution home treatment provided by older people's mental health services now show reductions in unplanned admissions, discharge to care homes, length of stay and high user satisfaction. ${ }^{1,24,25}$

General hospital liaison is a rare example of service development for older people, with services increasing from $27 \%$ of providers in $2003^{26}$ to $84 \%$ of commissioning areas now, with $91 \%$ considered to provide equality of access and $82 \%$ of the $91 \%$ provided by older people's mental health services. Validity of this increase can be found in the National Audit of Dementia when $88 \%$ of general hospitals in England reported access to a liaison psychiatry service that can assess older people and $81 \%$ of those provided by a dedicated team. ${ }^{27}$ This is an area of rising demand ${ }^{28}$ that has received a particular focus by old age psychiatrists, ${ }^{29,30}$ subsequently translated into national guidance. ${ }^{31-33}$ The economic and clinical benefits of liaison services is now being realised, with $90 \%$ of substantial cost savings arising from the care of older people. ${ }^{34}$

Preliminary findings from older people's CRHT, contrasting with doubt that younger adult CRHT has had any impact on reducing admission ${ }^{35}$ and the findings that $90 \%$ of cost savings from hospital liaison services arise from impact on older people, ${ }^{34}$ might suggest that the government has focused its investment on the wrong population.

The development of single age-inclusive services is curious. It has been suggested that this has arisen from a cynical response to meeting the cost pressures in the NHS at the expense of older people or a simple misunderstanding of the principles of equality. ${ }^{1}$ Curious, because it runs counter to the evidence base and national guidance. There is evidence that older people's mental health services are effective, with a lack of evidence for alternative approaches. ${ }^{36}$ The single age-inclusive service approach is not supported by guidance from the Royal College of Psychiatrists, Healthcare Commission or Department of Health, who caution against adopting a 'one size fits all' approach as a solution to age discrimination., ${ }^{1,9,16,18-22}$ Even the National Dementia Strategy expresses concern, describing the separation of organic and functional mental disorders in later life as a false dichotomy and emphasising that improvement of services for people with dementia must not be used as an excuse to dilute specialist services for older people with other mental health needs. ${ }^{32}$ These guidance documents recognise the lack of clinical rationale for a 'one size fits all' approach for older people where multimorbidity and complex needs are the norm. ${ }^{1}$

A further problem with single age-inclusive services is that it will become impossible to financially map investment in older people's mental health. Disaggregating outcomes by age will be an important measure of equality, as when data collection is based on a single grouping, even only people over age 65, this leads to an underestimate of poor 
emotional well-being, life satisfaction and mental health problems by concealing higher rates among older people whose numbers are increasing the most. ${ }^{37}$

\section{Strengths and limitations}

Strengths of this study include a high response rate $(76 \%),{ }^{38}$ with data covering a range of services from three countries. The high response rate may well be explained by having employed a short questionnaire of some interest to the participants. $^{39}$ Similar data have not previously been reported.

Weaknesses include single commissioning areas that may have multiple providers who provide services differently from one another (impossible to capture in this design) and equality of access being reliant on perception. There is a danger that equality is simply seen as a function of availability, even though the survey provided a more rigorous definition. We feel this is likely to underestimate inequality.

\section{Conclusions}

This survey confirms, in the eyes of commissioners, that inequality of access to mental health services for older people is widespread. Furthermore, the variation of response to the needs of older people confirms that the postcode lottery is prevalent. That the greatest degree of inequality is seen with services that have been preferentially developed for younger adults supports the notion that previous government policy implementation has been at the heart of this discrimination.

Inequality was more likely to be reported when older people were seen by a single age-inclusive service. The danger that this age-blind approach may result in indirect discrimination should be taken seriously and such a development that runs contrary to evidence or support from national guidance would need to be explained.

Health policy that has excluded older people has not only created discrimination and inequality but has missed a vital opportunity to improve clinical outcomes and costeffectiveness. ${ }^{1}$ Governments and commissioners have shown a surprising failure to realise the significance of the ageing population, adopt best practice and make service development for older people a national priority. Positive action that sees a shift of focus to mental health services that better meet the needs of older people may produce greater economic benefit. Certainly, the rising demand for these services is inevitable.

It is hoped that new government policy and discrimination legislation will form the basis on which age equality in mental health could be achieved, although this will have to be accompanied by a substantial change and more sophisticated approach to the way mental health services are configured, delivered and resourced. ${ }^{1,19}$

At the heart of this will need to be teams with competencies in older people's mental health. Service reconfiguration, driven by the pressure to reduce costs or a misguided interpretation of the age discrimination legislation that fails to meet the special needs of older people must be exposed, as they will neglect increasing morbidity among an ageing population that will ultimately cost more and create indirect discrimination. That ageinclusive services may simply convert direct discrimination into indirect discrimination (the chilling effect), which is more difficult to detect, should be a major concern for legislators, mental health services and the public.

\section{About the authors}

David Anderson, Consultant Old Age Psychiatrist, Mersey Care NHS Trust, Liverpool. Peter Connelly, Consultant Old Age Psychiatrist, Murray Royal Hospital, Perth. Richard Meier, former Policy Analyst for the Royal College of Psychiatrists, London. Cherie McCracken, Institute of Psychology, Health \& Society, University of Liverpool.

\section{References}

1 Anderson D, Banerjee S, Barker A, Connelly P, Junaid O, Series H, et al. The Need to Tackle Age Discrimination in Mental Health: A Compendium of Evidence. Royal College of Psychiatrists, 2009.

2 Beecham J, Knapp M, Fernandez J-L, Huxley P, Mangalore R, McCrone P, et al. Age Discrimination in Mental Health Services. Personal Social Services Research Unit, 2008.

3 Forder J. The Costs of Addressing Age Discrimination in Social Care. Personal Social Services Research Unit, 2008.

4 McCrone P, Dhanasiri S, Patel A, Knapp M, Lawton-Smith S. Paying the Price: The Cost of Mental Health Care in England to 2026. The Kings Fund, 2008.

5 Centre for Workforce Intelligence. Recommendation for Medical Specialty Training 2011. Centre for Workforce Intelligence, 2011.

6 Draper B, Anderson D. The baby boomers are nearly here - but do we have sufficient workforce in old age psychiatry? Int Psychogeriatrics 2010; 22: 947-9.

7 Department of Health. National Service Framework for Older People. TSO (The Stationery Office), 2001.

8 Tucker S, Baldwin R, Hughes J, Benbow S, Barker A, Burns A, et al. Old age mental health services in England: implementing the National Service Framework for Older People. Int J Geriatr Psychiatry 2007; 22 211-7.

9 Healthcare Commission. Equality in Later Life: A National Study of Older People's Mental Health Services. Healthcare Commission, 2009.

10 Department of Health. National Service Framework for Mental Health Modern Standards and Service Models. TSO (The Stationery Office), 1999.

11 Appleby L. Mental Health Ten Years On: Progress on Mental Health Care Reform. Department of Health, 2007.

12 Department of Health. 2009/10 National Survey of Investment in Adult Mental Health Services. Department of Health, 2012.

13 Mental Health Strategies. 2010/11 National Survey of Investment in Mental Health Services for Older People. Report Prepared for Department of Health. Mental Health Strategies, 2011.

14 Appleby L. National Service Framework for Mental Health: Five Years On. Department of Health, 2004.

15 Philp I. Better Health in Old Age. Department of Health, 2004.

16 Department of Health. No Health Without Mental Health: A Crossgovernment Mental Health Outcomes Strategy for People of All Ages. HM Government, 2011

17 Anderson D. Age discrimination in mental health services needs to be understood. Psychiatrist 2011; 35: 1-4.

18 NHS Southwest. Achieving Age Equality in Health and Social Care: NHS Practice Guide. Department of Health.

19 Royal College of Psychiatrists. Age Discrimination in Mental Health Services: Making Equality a Reality (Position Statement PS2/2009). Royal College of Psychiatrists, 2009. 
20 Royal College of Psychiatrists. The Equality Act 2010 and Adult Mental Health Services: Achieving Non-discriminatory Age Appropriate Services (Occasional Paper OP82). Royal College of Psychiatrists, 2011.

21 Carruthers I, Ormondroyd J. Achieving Age Equality in Health and Social Care. Department of Health, 2009.

22 Department of Health/Care Services Improvement Partnership. Age Equality: What Does it Mean for Older People's Mental Health Services? Department of Health, 2007.

23 Cooper C, Regan C, Tandy AR, Johnson S, Livingstone G. Acute mental health care for older people by crisis resolution teams in England. Int $J$ Geriatr Psychiatry 2007; 22: 263-5.

24 Dibben C, Saeed H, Stagias K, Khandaker GM, Rubinsztein JS. Crisis resolution and home treatment teams for older people with mental illness. Psychiatr Bull 2008; 32: 268-70.

25 Fraser K, Clark M, Benbow SM, Williams G, Burchess I. Old age psychiatry home treatment team - preliminary audit of services improvement project. Int J Geriatr Psychiatry 2009; 24: 648-52.

26 Holmes J, Bentley K, Cameron I. A UK survey of psychiatric services for older people in general hospitals. Int J Geriatr Psychiatry 2003; 18: 716-21.

27 Royal College of Psychiatrists Centre for Quality Improvement. Report of the National Audit of Dementia Care in General Hospitals 2011. Royal College of Psychiatrists, 2011

28 Anderson D, Nortcliffe M, Duchenne S, Wilson K. The rising demand for consultation-liaison psychiatry for older people: comparisons within Liverpool and the literature across time. Int J Geriatr Psychiatry 2011; 26: 1231-5.

29 Faculty of Old Age Psychiatry. Who Cares Wins. Improving the Outcome for Older People Admitted to the General Hospital: Guidelines for the
Development of Liaison Mental Health Services for Older People. Royal College of Psychiatrists, 2005.

30 Anderson D, Holmes J. Liaison psychiatry for older people - an overlooked opportunity. Age Ageing 2005; 34: 205-7.

31 National Institute for Health and Clinical Excellence, Social Care Institute for Excellence. Dementia: Supporting People with Dementia and their Carers in Health and Social Care (amended March 2011). National Collaborating Centre for Mental Health, 2006.

32 Department of Health. Living Well with Dementia: A National Dementia Strategy. Department of Health, 2009.

33 National Institute for Health and Clinical Excellence. Dementia Quality Standards. NICE, 2010.

34 Parsonage M, Fossey M. Economic Evaluation of a Liaison Psychiatry Service. Centre for Mental Health, 2011.

35 Jacobs R, Barrenho E. Impact of crisis resolution and home treatment teams on psychiatric admissions in England. Br J Psychiatry 2011; 199: $71-6$.

36 Draper B. The effectiveness of old age psychiatry services. Int J Geriatric Psychiatry 2000; 15: 687-70.

37 Allen J. Older People and Wellbeing. Institute for Public Policy Research, 2008.

38 Asch D, Jedrziewski M, Cristakis N. Response rates to mail surveys published in medical journals. J Clin Epidemiol 1997; 50: 1129-36.

39 Edwards P, Roberts I, Clarke M, DiGuiseppi C, Pratap S, Wentz R, et al Increasing response rates to postal questionnaires: systematic review. BMJ 2002; 324: 1183-91.

\section{Psyechiatrist}

